\title{
Review \\ High avidity autoreactive T cells with a low signalling capacity through the T-cell receptor: central to rheumatoid arthritis pathogenesis?
}

\author{
Ranjeny Thomas ${ }^{1}$, Malcolm Turner ${ }^{1}$ and Andrew P Cope ${ }^{2}$ \\ 1Diamantina Institute for Cancer, Immunology and Metabolic Medicine, University of Queensland, Princess Alexandra Hospital, Brisbane, Queensland, \\ 4102, Australia \\ 2The Kennedy Institute of Rheumatology, Faculty of Medicine, Imperial College, 1 Aspenlea Road, Hammersmith, London W6 8LH, UK
}

Corresponding author: Ranjeny Thomas, r.thomas1@uq.edu.au

Published: 24 July 2008

This article is online at http://arthritis-research.com/content/10/4/210

(c) 2008 BioMed Central Ltd
Arthritis Research \& Therapy 2008, 10:210 (doi:10.1186/ar2446)

\section{Thymic selection and the predisposition to autoimmunity}

Central (or thymic) tolerance defects are important and probably essential contributors to spontaneous autoimmune disease [4]. T cells are selected in the thymus according to their affinity for self-MHC (major histocompatibility complex) bearing endogenous self-antigens displayed by the thymic cortical epithelial cells. Negative selection then deletes those $T$ cells that are reactive to self-antigen above a threshold of affinity for self-antigen/MHC complexes expressed and presented by medullary antigen-presenting cells (APCs), notably medullary epithelial cells and medullary DCs [5].

\section{Introduction}

In 1996, Thomas and Lipsky [1] proposed a model for rheumatoid arthritis (RA) pathogenesis in which endogenous self-antigens were presented by activated peripheral dendritic cells (DCs) to autoreactive T cells that had escaped thymic selection. Synovial DCs were shown to be activated, probably as a consequence of proinflammatory signals derived from the RA joint environment, including cytokines and T-cell derived CD40 ligand [1,2]. The model stemmed from observations that autologous peripheral blood $T$ cells proliferated strongly in vitro in response to RA synovial DCs presenting endogenous antigenic peptide (known as the autologous mixed lymphocyte response). At that time it was unclear how $T$ cells with the capacity to respond strongly to self-antigen might escape thymic deletion and enter the peripheral repertoire. However, the subsequent discovery by Sakaguchi and colleagues [3] of a spontaneous mouse mutant, known as 'SKG', which developed inflammatory arthritis resembling RA, has provided a possible mechanism.
In the medulla, medullary epithelial cells express the highest levels of autoimmune regulator (AIRE), a transcription factor that controls the expression of peripheral tissue antigens. In the absence of AIRE, glandular (salivary and lacrimal glands, liver, pancreas and thyroid) organ-specific autoimmunity develops [6]. Interestingly, neither mice nor humans with AIRE mutations develop autoimmune arthritis, possibly because AIRE does not directly regulate the expression of joint-specific self-proteins in the thymus.

Medullary DCs have also been shown to delete self-reactive T cells in the thymus in experimental settings [7], but abnormalities in these cells have not yet been implicated in any spontaneous autoimmune model. Although the spectrum they can capture antigen from peripheral tissues - presumably including synovial joints - and delete self-antigen-specific thymocytes in the medulla. of self-antigen presentation by medullary DCs is unknown,

$\mathrm{ACPA}=$ antibody to citrullinated proteins; AIRE = autoimmune regulator; $\mathrm{APC}=$ antigen-presenting cell; $\mathrm{CTL}=$ cytotoxic $\mathrm{T}$ lymphocyte; $\mathrm{DC}=$ dendritic cell; EBV = Epstein-Barr virus; HA = haemagglutin antigen; HLA = human leucocyte antigen; IFN = interferon; IL = interleukin; LPS = lipopolysaccharide; $\mathrm{MHC}=$ major histocompatibility complex; NF- $\mathrm{KB}=$ nuclear factor- $\mathrm{KB} ; \mathrm{RA}=$ rheumatoid arthritis; $\mathrm{RF}=$ rheumatoid factor; SNP = single nucleotide polymorphism; TCR $=\mathrm{T}$-cell receptor; TLR $=$ Toll-like receptor; TNF $=$ tumour necrosis factor; ZAP-70 $=\zeta$-associated protein of $70 \mathrm{kDa}$. 
Although an affinity threshold applies for central deletion of self-reactive $\mathrm{T}$ cells, this threshold varies according to the susceptibility of thymocytes to death and the capacity of the T-cell receptor (TCR) and downstream pathways to transmit an activation signal. Moreover, the efficiency of self-antigen presentation depends on the ability of thymic APCs to process and present self-antigen, and the density of $\mathrm{MHC}$ and co-stimulatory molecules on the APC surface.

A number of well established spontaneous animal models of autoimmunity are characterized by defects in the normal process of either positive or negative selection, thus permitting the entry of autoreactive $T$ cells into the peripheral repertoire. In the periphery, subsequent genetic or environmental proinflammatory events more readily trigger the activation of these $\mathrm{T}$ cells, and thus the development of autoimmune disease [8]. Does this scenario fit the SKG RA model or human RA itself?

TCR signalling is dramatically attenuated in the SKG mouse model of spontaneous arthritis. This is due to a mutation in the $\mathrm{SH} 2$ domain of the gene encoding $\zeta$-associated protein of $70 \mathrm{kDa}$ (ZAP-70), a TCR proximal protein tyrosine kinase that is essential for T-cell activation after the TCR engages antigen [3]. Experiments using TCR transgenic mice show that high-affinity self-reactive $T$ cells escape negative selection in these mice. At the same time, defective TCR signalling also attenuates positive selection, reducing the peripheral T-cell pool compared with wild-type mice (Figure 1). The abnormal peripheral T-cell repertoire, comprising a higher proportion of self-reactive $\mathrm{T}$ cells than in wild-type mice, is demonstrable ex vivo, because peripheral SKG T cells incubated with autologous APC proliferate vigourously in spite of the ZAP-70 mutation, and secrete IL-17 in the autologous mixed lymphocyte response [9]. SKG mice develop spontaneous rheumatoid factor (RF)-positive inflammatory arthritis, resembling RA in patients, when housed in a conventional animal facility where environmental pathogen exposure might occur at low levels. Conversely, in a microbiologically clean facility, mice do not develop joint disease, although RF and other autoantibodies are still detectable [3,9].

In an elegant follow-up study, Sakaguchi and coworkers [9] showed that subclinical fungal infection is predominantly responsible for the inflammatory signals that drive spontaneous joint disease in SKG mice. $\beta$-Glucan molecules derived from the fungal cell wall signal through the dectin-1 cell surface C-type lectin receptor on the cell surface of antigen-presenting DCs. Reis e Sousa and colleagues [10] demonstrated that signalling of murine DCs though the dectin-1 receptor promotes the secretion of proinflammatory cytokines, including IL-6, tumour necrosis factor (TNF) and IL23, but little IL-12. In SKG mice, such DCs activated by dectin-1 promote the in vitro and in vivo differentiation of CD4+ T-effector cells secreting IL-17 [9]. Lymphopenia may be an important contributor to the self-reactive response in this case because it promotes homeostatic proliferation of effector $\mathrm{T}$ cells, similar to that demonstrated in other autoimmune models $[11,12]$.

\section{T-cell phenotype and function}

CD4+ SKG $\mathrm{T}$ cells in the periphery exhibit a phenotype characteristic of antigen-experienced, post-activated cells, as are typically observed in autoimmune arthritis. There are increased proportions of CD44hi, $\mathrm{CD}^{4} 5^{+}, \mathrm{CD}^{4} 9^{+}, \mathrm{OX} 40^{+}$ and CD45RBdim cells, as compared with the proportions in wild-type BALB/c littermates [3]. When adoptively transferred to lymphopenic hosts, SKG T cells proliferate just as efficiently as wild-type T cells [9]. Although both SKG and wild-type T-cell subsets produce similar proportions of T-helper-17 and T-helper-1 effectors under these conditions, SKG T cells are more strongly self-reactive than wild-type T cells [9].

Another murine model of spontaneous inflammatory arthritis that fits this paradigm was reported very recently. In the $F_{1}$ progeny of BALB/c mice containing both haemagglutin antigen (HA)-specific TCR-transgenic $\mathrm{CD}^{+}{ }^{+} \mathrm{T}$ cells and $\mathrm{HA}$ driven by a MHC class II-specific promoter (known as TS1 $\times$ HACll mice) [13], high-affinity HA-specific T cells are negatively selected in the thymus, but low-affinity HA-specific $T$ cells bearing low levels of cell surface TCR expand in the periphery over time. Similar to SKG T cells, these CD4+ $T$ cells exhibit a post-activated memory phenotype, with low proliferative capacity but high capacity for cytokine production in response to antigen stimulation ex vivo. The mice develop a T-cell-dependent and B-cell-independent peripheral arthritis, pneumonitis and cardiac inflammation from around 6 weeks of age, with a gradual progression in severity. The disease phenotype is similar to other spontaneous arthritis models (but unlike autoimmune models in which AIRE is deficient), which lack endocrine or glandular multi-organ inflammatory pathology.

It is striking that autoantigen-experienced memory $\mathrm{CD} 4^{+}$cells with low TCR signalling capacity are particularly associated with autoimmune arthritis. However, the relative joint specificity arising from immunity toward an antigen whose expression is not joint restricted is puzzling. We speculate that the capacity of such $\mathrm{T}$ cells to secrete relevant cytokines (including IFN- $\gamma, \mathrm{IL}-17$ and TNF [13]), in concert with tissuespecific homing properties, might underlie the induction of arthritis. The extent to which joint stromal cells (including synovial fibroblasts) are exquisitely sensitive to cytokine stimulation, as compared with stromal cells from other tissues, remains a matter of debate.

In RA, antigen-experienced synovial $\mathrm{T}$ cells, with a similar

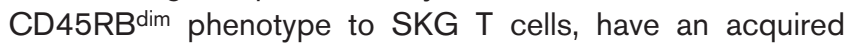
TCR signalling deficiency. We previously showed that synovial T cells proliferated poorly and secreted low levels of IL-2 in vitro [14]. The reduced T-cell proliferation seen in RA 




(b)

RA

THYMUS

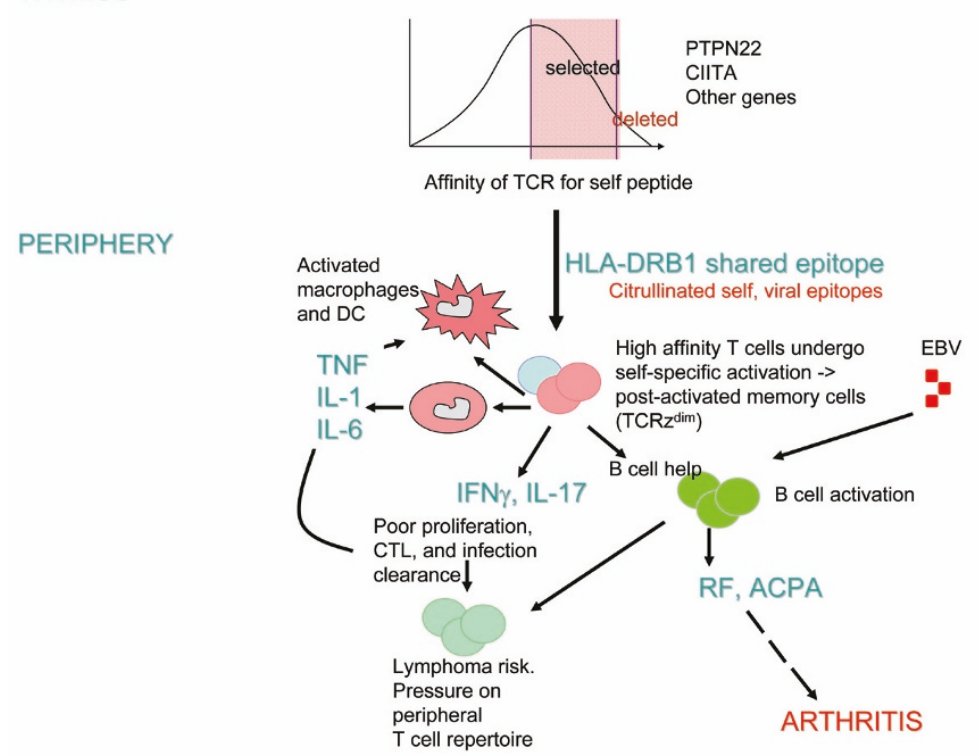

Pathogenesis of inflammatory arthritis. (a) The SKG model and (b) a model for rheumatoid arthritis (RA) suggested by the skg mouse. As a result of altered thymic selection, the peripheral T-cell repertoire responds to self-antigen with higher affinity compared with the healthy situation, facilitating self-specific activation and population of the periphery with post-activated memory $T$ cells. These $T$ cells produce proinflammatory cytokines and provide efficient help for autoantibody production, but they have limited capacity for infection control. Antigen-presenting dendritic cells (DCs) are activated directly by fungal $\beta$-glucans (panel a) or indirectly through T cells or proinflammatory cytokines (panels a and b). ACPA, antibodies to citrullinated protein; CTL, cytotoxic T lymphocyte; EBV, Epstein-Barr virus; IFN, interferon; IL, interleukin; RF, rheumatoid factor; TCR, T-cell receptor; TNF, tumour necrosis factor; WT, wild-type.

is also associated with reduced TCR signal intensity, reduced calcium signalling and reduced expression of TCR- $\zeta$. It has been shown that TCR- $\zeta$ chains are either not expressed or lack phosphorylation in RA synovial fluid T cells. TCR- $\zeta$ chain 
expression levels correlated with RA T-cell responsiveness [15]. We previously defined populations of TCR- $\zeta \operatorname{dim} T$ cells in peripheral blood with characteristics of prior antigen experience, based on cell surface phenotype, cytokine expression and migratory competence [16]. In chronic inflammatory diseases (for example, RA and systemic lupus erythematosus) it has been proposed that an inflammatory milieu contributes to reduction in TCR- $\zeta$ expression in antigenexperienced T cells. Inflammatory factors that could contribute to this process in predisposed individuals include nutrient depletion, increased expression of reactive oxygen intermediates such as $\mathrm{H}_{2} \mathrm{O}_{2}$, and induction of stress pathways [17]. Genetic, acquired and age-related factors could thus contribute to a state of chronic TCR signalling deficiency in RA.

In contrast, IFN- $\gamma$ and IL-17 production by RA T cells appears to be spared $[16,18,19]$. In addition, synovial $T$ cells potently induce B cells to secrete autoantibodies [14] and activate synovial macrophages, DCs and resident stromal cells. These cells, in turn, express inflammatory cytokines and chemokines through cell contact-dependent mechanisms [20]. Thus, in spite of their TCR signalling deficiencies, synovial T cells can promote chronic inflammation within the synovial lesion, stimulating B cells, and promoting macrophage and DC activation and robust secretion of cytokines. Beyond these acquired signalling defects, is there any evidence that low TCR signalling capacity might precede RA?

\section{Genetic provocation of autoreactive T cells with low TCR signalling capacity}

The primary genetic defect in the SKG autoimmune arthritic mouse model is a point mutation in the TCR proximal protein tyrosine kinase ZAP-70. This mutation does not alter ZAP-70 expression, but nevertheless it dramatically reduces the affinity of the carboxyl-terminal $\mathrm{SH} 2$ domain of ZAP-70 in binding phosphorylated tyrosine residues in the immunoreceptor tyrosine-based activation motif (ITAM) modules of the TCR- $\zeta$ chain [3]. This mutation can therefore entirely account for the thymic selection shift and the generation of a repertoire of autoreactive $\mathrm{T}$ cells with a high avidity for selfantigen/MHC complexes in SKG mice. However, the question arises as to whether there are similar (or functionally related) mutations in RA.

To date, no allelic variants of the human ZAP70 gene have been described in association with RA or in association with any other known immune-mediated inflammatory disease. In contrast, attention has recently focused on elucidating the function of the PTPN22 gene that encodes a protein tyrosine phosphatase called LYP (lymphocyte tyrosine phosphatase) [21]. The R620W variant of this gene is, somewhat unexpectedly, a gain-of-function mutant that reduces TCR signalling capacity. Functional data from healthy donors homozygous or heterozygous for the R620W mutation confirm that peripheral blood $\mathrm{T}$ cells are hyporesponsive to antigen receptor stimulation. This polymorphism would thus be predicted to impair positive and negative selection of autoreactive T cells $[22,23]$. Within the context of SKG and RA T cells, it is interesting that carriage of the variant allele was also associated with reduced $\mathrm{IL}-10$ production and an increase in the numbers of $\mathrm{CD}^{+}$memory $\mathrm{T}$ cells, potentially associated with increased self-reactivity. Expression of TNF- $\alpha$ and IFN- $\gamma$ was unaffected [23]. As a result of altered thymic selection, this phenomenon might arise through increased intrinsic responsiveness and augmented generation of effector $\mathrm{T}$ cells that recognize endogenous self-peptides presented by APCs in vivo. A complementary possibility is that gain-offunction PTPN22 mutants suppress TCR signalling in natural regulatory $T$ cells and thus impair peripheral tolerance. RA has also been associated with single nucleotide polymorphisms (SNPs) in the MHC class II transactivator gene (MHC2TA). These SNPs are predicted to reduce the efficiency of self-antigen presentation by APCs in the thymus and periphery, with effects on the T-cell repertoire similar to those associated with PTPN22 R620W [24]. These alterations in the repertoire of healthy individuals with PTPN22 R620W suggest that a low TCR signalling capacity may predispose otherwise healthy individuals to RA, just as SKG mice are predisposed to (but do not develop) arthritis in the absence of infection.

\section{Presentation of self-antigen to autoreactive $T$ cells promoting rheumatoid arthritis depends on activation of dendritic cells}

Activated DCs play several roles in autoimmune arthritis. They serve as APCs for T-cell priming, as accessory cells in the generation of primary antibody responses, and as producers of proinflammatory cytokines (alongside synoviocytes and macrophages) [25-27]. DCs infiltrate inflamed tissue, take up and process antigen locally, and then activate MHC-restricted naïve $T$ cells in draining lymph nodes [1,27-30]. In turn, autoreactive primed $\mathrm{T}$ cells co-stimulate $\mathrm{DC}$ activation particularly through CD40 ligand, reinforcing the autoimmune response that eventually leads to excessive autoantibody production and chronic inflammation associated with RA [2]. DCs are activated by the uptake of immunogenic antigen, pathogen and damage recognition ligands, a role played - at least in part - by fungal $\beta$-glucan signalling through dectin- 1 in SKG mice [31-33]. Proinflammatory cytokines also activate DCs, although evidence is emerging that the gene activation programme is in this instance different from that activated by pathogen or lipopolysaccharide (LPS) [34]. Are DCs activated in RA, how does this come about, and how do highavidity autoreactive $T$ cells respond?

SKG, TS1 1 HACIl mice and RA DCs and macrophages share a capacity for 'hyper-activation'. This activation is enhanced by strong positive feedback from post-activated memory $\mathrm{T}$ cells, by immune complex ligation of $\mathrm{Fc}$ receptors and by proinflammatory cytokines $[9,13]$. DCs and macrophages from the synovial fluid of RA patients exhibit an unusual and

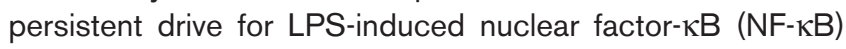


activation ex vivo $[35,36]$, apparently in the face of strong signals for exhaustion and counter-regulation that would normally halt activation [37,38]. This hyper-activation contrasts with monocytes and DCs isolated from patients with type 1 diabetes, which we have shown shut down $\mathrm{NF}-\kappa \mathrm{B}$ in response to LPS [39]. Although it has only been technically feasible to examine peripheral blood DCs from patients with diabetes, when we compared peripheral blood DCs from RA patients we did not find a similar exhausted response to LPS in RA [39]. In a murine model, a Toll-like receptor (TLR)4-mediated signalling pathway blocked TLR ligand responsiveness and promoted an exhausted phenotype. In the absence of TLR4 signalling, DCs exposed to proinflammatory cytokines in vivo could be further activated ex vivo by other TLR ligands [34]. Although the mechanism distinguishing the responsiveness of RA and diabetes DCs to LPS is not yet clear, the implication is that DCs would present antigen more efficiently in the face of infection or other proinflammatory events in RA, whereas they would be less effective in response to the same stimuli in diabetes. DC hyperactivity appears to be characteristic of the pathogenesis of autoimmune arthritis in both RA and the described murine models.

\section{MHC-peptide interactions with T cells in RA}

Variation in the HLA-DRB1 gene of the $\mathrm{MHC}$ is more strongly associated with RA than variation in any other locus. The variation maps to the third hypervariable region of the DR $\beta$ chain and is found in many different human leucocyte antigen (HLA)-DR molecules linked to RA [40]. The locus encodes a conserved susceptibility sequence - known as the 'shared epitope' - that is positively charged and forms the fourth anchoring pocket (P4) in the HLA-DR peptide binding groove [41]. Antibodies to citrullinated proteins (ACPAs) and RF are more likely in RA patients with the shared epitope and who smoke [42-44]. Thus, it has been proposed, in view of evidence that smoking promotes citrullination of self-proteins in the lung, that smoking promotes ACPAs in those with atrisk HLA genotypes [43]. We found that peripheral blood T cells from patients with RA susceptibility HLA-DR alleles and ACPAs proliferated poorly in response to specific shared epitope-associated citrullinated peptides, consistent with low signal capacity through the TCR. However, the T cells strongly induced proinflammatory cytokine secretion in response to these peptides as well as the native form of these epitopes. Surprisingly, these responses occurred at very low concentrations of peptide, suggestive of high-affinity anti-self-responses (Capini $\mathrm{C}$ and coworkers, unpublished data). We therefore propose that subsets of self-reactive $\mathrm{T}$ cells that interact with high-avidity with peptide-MHC may compensate for attenuated TCR signalling, which is consistent with our ex vivo observations that T cells from RA patients respond with high avidity to citrullinated and noncitrullinated self-antigens. Expression of CD70 by antigen-experienced $T$ cells may be at least one mechanism by which antigen-specific responses may be augmented [45].
This ongoing autoreactivity would result in the contraction of the T-cell repertoire and highly selective expansion of selfreactive $\mathrm{T}$-cell clones.

\section{Chronic inflammation and the tumour necrosis factor/nuclear factor- $\kappa B$ drive in rheumatoid arthritis}

Based on human and animal data, what are the key factors that drive chronic inflammation in RA? Experiments in different animal arthritic models, including TNF transgenic mice, and IL-1 receptor antagonist knockout and p50 knockout mice, indicate that proinflammatory stimuli driving the expression of TNF, IL-1, or NF- $\mathrm{KB}$ p50 are sufficient to drive the development of autoimmune polyarthritis in susceptible strains [46-49]. NF- $\kappa B$ stimulates the transcription of genes important for cellular responses to stress, injury and inflammation [50], and thus NF- $\mathrm{KB}$ signalling simultaneously sustains synovial inflammation and promotes DC and monocyte activation and differentiation, resulting in priming of autoreactive lymphocytes. We and others have provided additional evidence that TNF and IL-1 directly enhance B-cell and $\mathrm{T}$-cell autoreactivity through effects on regulatory $\mathrm{T}$ cells [51-53]. Nicotine, lactation, mineral oil exposure and EpsteinBarr virus (EBV) - environmental factors associated with RA all promote NF- $\kappa B$ activity, associated with TNF and IL-1 secretion by myeloid and stromal cells, and DC and B-cell activation [54-57].

On the other hand, combinations of disease-modifying antirheumatic drugs and biologic therapies that suppress the activity of NF- $\mathrm{KB}$ can induce RA remission [58,59]. Thus, both human and murine evidence indicates that NF- $\mathrm{B}$ activation is required to drive $\mathrm{RA}$, and that factors that suppress this activity are disease suppressive [48,60,61]. TNF clearly plays a critical role in RA perpetuation, activating and being activated by NF- $\mathrm{KB}$ in a positive feedback loop.

\section{Genetic and environmental provocation of strong activation of innate immunity and antigen presentation}

There are links between RA and NF- $\kappa B$ driven genes of the innate immune response involved in pathogen recognition, proinflammatory cytokine production and modulation of the strength of cellular signalling in response to activation signals. RA-associated SNPs have been detected in complement-5-TRAF1, STAT 4 and in DCIR, another lectin receptor that is expressed on the surface of DCs [62-65]. Identification of these SNPs has potential implications for the way in which we assess the impact of environmental RA risk factors - such as infection and tobacco smoke - in individuals genetically predisposed to RA. Apart from direct cellular effects, tissue damage caused by tobacco smoke or infection also provoke the release of endogenous pathogen recognition receptor ligands derived from host cellular debris (also known as damage-associated molecular patterns or DAMPs). These have been shown to function as auto-adjuvants, which 
both perpetuate and reinforce the inflammatory response and stimulate the APC function of DCs.

\section{The role of viral pathogens in driving nuclear factor- $\kappa B$}

EBV, which infects about $98 \%$ of the world's population, has the strongest viral association with RA [66,67]. Almost all the arthritogenic viruses, including EBV, rubella, parvovirus B19, hepatitis B and C, HIV, HTLV1 and Ross River Fever, activate $\mathrm{NF}-\mathrm{\kappa B}$ in order to replicate, suggesting the possibility that arthritis develops as a side-effect of NF-KB activation. These viruses manipulate the NF-KB pathway to enhance their replication and host cell survival, while blocking apoptosis and immune recognition [68]. The EBV latent membrane protein-1 activates NF- $\mathrm{KB}$ through interaction with TNF receptor 1 and the TNF receptor 1 -associated death domain. Activation bypasses the cytoplasmic TNF signalling pathway [68]. NF-KB activation by EBV allows it to evade the normal host responses and leads to a persistent low-grade B-cell infection. EBV DNA has been detected in synovial tissue from RA patients, using polymerase chain reaction, in situ hybridization and immunohistochemical staining [69]. EBV latent membrane protein-1 has also been demonstrated in RA synoviocytes and lymphocytes. The EBV Epstein-Barr nuclear antigen (EBNA)-1 protein also undergoes citrullination. Thus, EBV can induce antibodies to citrullinated peptides [70,71]. The EBV capsid protein gp110 also contains the shared epitope sequence [72]. The evidence suggests there is a deficiency in viral control coincident with RA, which is consistent with a host immunodeficient state. In RA patients, there are increased numbers of EBV-infected B lymphocytes, higher specific antibody titres, and impaired EBV-specific cytotoxic T lymphocyte (CTL) activity, as compared with otherwise healthy EBV-infected individuals $[73,74]$.

We propose that simultaneous NF- $\mathrm{KB}$ stimulation by viral infection and RA results in a 'mutually permissive' state, with viral infection promoting RA disease, and vice versa, through $\mathrm{NF}-\mathrm{\kappa B}$. The key question is whether patients at risk for RA are also at greater risk for immune dysregulation during EBV infection. For us, the evidence is in favour. Hijacking of $B$ lymphocyte cellular machinery by EBV promotes chronic dysregulated immune activation with increased NF- $\mathrm{KB}$ activity, and the propensity both for B-cell autoantibody secretion and lymphoma development [69]. Because EBV infection activates the NF-KB pathway in B lymphocytes, they are prone to apoptotic cell death in response to NF-KB inhibition during RA treatment [75]. Furthermore, in those predisposed to RA, EBV infection may persist through a state of relative immunodeficiency imposed by attenuated TCR signals, reducing the efficacy of EBV-specific CTLs. Functional CTLs are essential for effective control of EBV-associated lymphoproliferative disease in post-transplant settings [76]. This immune dysregulation associated with failure of normal T-cellmediated infection control in RA might explain how RA inflammatory disease can appear T-cell independent, as indicated by poor clinical responses to T-cell-depleting therapies. On the other hand, strategies such as CTLA4-Ig (CTL antigen 4-immunoglobulin), which specifically target a T-cell-dependent pathway, are effective because they probably confer desirable immuno-regulation on the multiple sites of T-cell action.

\section{Synthesis: similarity and differences in pathogenesis of arthritis in SKG mice and RA}

Pathogenic T cells from both SKG and TS1 $\times$ HACll mice and RA patients appear to share the following characteristics: a reduced capacity for TCR signalling; increased proportions of $T$ cells with a post-activated differentiated memory phenotype; a reduced capacity for proliferation and IL-2 production, despite their capacity for IL-17 and IFN- $\gamma$ secretion; enhanced B-cell help and a strong capacity for autoantibody production; and an enhanced response to self-antigens. Figure 1 depicts models of disease pathogenesis in SKG mice and RA patients, highlighting their similarities and some differences.

Clearly, in the SKG model it is easier to ascertain that low TCR signalling capacity underlies arthritis development. In RA, although we have argued that secondary TCR signalling deficiencies provide a positive feedback loop for inflammation, it will be of interest to determine whether similar TCR signalling deficiencies precede inflammatory disease, for instance whether they are evident in otherwise healthy individuals who are ACPA positive and at risk for RA. Further evidence could be obtained from patients achieving drug-free remission from chronic inflammation, such as after allogeneic stem cell transplantation. Although we have argued that infection plays a role in SKG mice and RA patients, the nature of this role appears to be different in each setting, with more direct inflammatory signalling of DCs in SKG mice. Indeed, we believe that if infectious or TLR-mediated damage signals are involved in driving $D C$ and macrophage activation in RA, as appears to be the case in SKG mice, then the usual counter-regulatory response to TLR activation must be attenuated. The development of arthritis in TS1 $\times$ HACll mice even in a microbiologically clean facility [13] indicates that infectious signals are not required to drive arthritis within the context of autoantigenic $T$ cells with reduced TCR signalling capacity. We propose that arthritis in this model develops independent of a pathogen drive because of the very high precursor frequency of autoantigen-specific $\mathrm{T}$ cells. In contrast, the reduced frequency of $\mathrm{T}$ cells specific for arthritogenic autoantigen among the polyclonal T-cell repertoire in the SKG mice, or indeed in RA, is less likely to provide sufficient feedback to DCs to drive spontaneous inflammation.

In RA, we propose that infection is intimately associated with the HLA susceptibility locus. Shared epitope alleles are common in the Caucasian population but they are strongly associated with RA, along with the development of both RF and ACPAs, and with severe erosive clinical disease. Why 
does shared epitope-associated RA persist at a frequency of around $1 \%$ in the population? We propose that the HLA susceptibility illuminates a bigger picture than the unfortunate side effect of joint autoimmunity. The polymorphic HLA genes evolved as a result of selection pressure by infection, and the shared epitope alleles thus identify individuals with particular immunity to infection. Our hypothesis is that EBV infection sets up a particularly 'cosy' symbiotic relationship with hosts bearing HLA susceptibility alleles and primary TCR signalling deficiency. As a result of EBV infection, persistent presentation of viral antigens could impose pressure on the T-cell repertoire, contributing with self-antigen presentation to drive expansion of an activated memory population, which further acquires inflammation-associated TCR signalling defects.

This phenomenon may underlie the observed thymic and bone marrow stem cell deficiency, excessive production of CD28null and other post-activated, terminally differentiated memory $\mathrm{T}$ cell phenotypes, hyper-activated DCs and B cells, and excess numbers of EBV-associated lymphomas and other tumours in RA patients [77]. Indeed, when synovial fluid $\mathrm{T}$ cells from RA patients were analyzed using EBV $\mathrm{MHC}$ class I tetramers, they were found to contain a high proportion of virus-specific T cells with an activated phenotype [78]. As might have been predicted, it was the differentiated $\mathrm{CD}^{+} \mathrm{CD} 28^{\text {null }} \mathrm{T}$-cell population that could be isolated from RA patients after stimulation with immunodominant lytic peptide EBV epitopes [79]. It is likely that EBV is not the only infection to result in a mutually permissive state of autoreactivity in RA. Other examples include the increased probability of RF production in patients with chronic HCV or with ageing, because the $\mathrm{T}$-cell repertoire is progressively populated with a higher proportion of post-activated memory T cells, creating a positive feedback loop as TCR signalling capacity decreases.

\section{Conclusion}

Although the SKG mouse model is by no means identical to human RA, it does mirror aspects of pathogenesis relating to gene-environment interactions that are involved in promoting autoimmune arthritis. This forces us to confront the paradox of how T cells with low TCR signalling capacity nevertheless interact with APCs and thus play initiating and continuing roles in the generation of autoimmune inflammation in RA patients. An improved understanding of the primary pathogenetic mechanisms of T cells in RA will probably have important implications for the design of effective and safe immunotherapies.

\section{Competing interests}

The authors declare that they have no competing interests.

\section{Acknowledgements}

We thank Caetano Reis e Sousa (funded by Cancer Research UK) for helpful discussions, and William Burns and lan Frazer (both funded by University of Queensland) for critical reading of the manuscript. Ranjeny Thomas is supported by Arthritis Queensland and Andrew Cope by Wellcome Trust UK and the Arthritis Research Campaign UK.

\section{References}

1. Thomas R, Lipsky PE: Could endogenous self-peptides presented by dendritic cells initiate rheumatoid arthritis? Immunol Today 1996, 17:559-564.

2. MacDonald KPA, Nishioka N, Lipsky PE, Thomas R: Functional CD40-ligand is expressed by $\mathrm{T}$ cells in rheumatoid arthritis. $J$ Clin Invest 1997, 100:2404-2414.

3. Sakaguchi N, Takahashi T, Hata H, Nomura T, Tagami T, Yamazaki S, Sakihama T, Matsutani T, Negishi I, Nakatsuru S, Sakaguchi S: Altered thymic T-cell selection due to a mutation of the ZAP70 gene causes autoimmune arthritis in mice. Nature 2003 , 426:454-460.

4. Ardavin C: Thymic dendritic cells. Immunol Today 1997, 18: 350-361.

5. Kappler JW, Roehm N, Marrack P: T cell tolerance by clonal elimination in the thymus. Cell 1987, 49:273-280.

6. Mathis D, Benoist C: A decade of AIRE. Nat Rev Immunol 2007, 7:645-650.

7. Bonasio R, Scimone ML, Schaerli P, Grabie N, Lichtman AH, von Andrian UH: Clonal deletion of thymocytes by circulating dendritic cells homing to the thymus. Nat Immunol 2006, 7:10921100.

8. Yoshitomi H, Sakaguchi N, Kobayashi K, Brown GD, Tagami T, Sakihama T, Hirota K, Tanaka S, Nomura T, Miki I, Gordon S, Akira S, Nakamura T, Sakaguchi S: A role for fungal beta\}-glucans and their receptor Dectin-1 in the induction of autoimmune arthritis in genetically susceptible mice. J Exp Med 2005, 201: 949-960.

9. Hirota K, Hashimoto M, Yoshitomi H, Tanaka S, Nomura T, Yamaguchi T, Iwakura Y, Sakaguchi N, Sakaguchi S: T cell self-reactivity forms a cytokine milieu for spontaneous development of $\mathrm{IL}-17^{+}$Th cells that cause autoimmune arthritis. J Exp Med 2007, 204:41-47.

10. LeibundGut-Landmann S, Gross O, Robinson MJ, Osorio F, Slack EC, Tsoni SV, Schweighoffer E, Tybulewicz V, Brown GD, Ruland J, Reis e Sousa C: Syk- and CARD9-dependent coupling of innate immunity to the induction of $T$ helper cells that produce interleukin 17. Nat Immunol 2007, 8:630-638.

11. Koh WP, Chan E, Scott K, McCaughan G, France M, Fazekas de St Groth B: TCR-mediated involvement of CD4+ transgenic T cells in spontaneous inflammatory bowel disease in lymphopenic mice. J Immunol 1999, 162:7208-7216.

12. Cozzo C, Larkin J, 3rd, Caton AJ: Self-peptides drive the peripheral expansion of CD4+CD25+ regulatory T cells. J Immunol 2003, 171:5678-5682.

13. Rankin AL, Reed AJ, Oh S, Cozzo Picca C, Guay HM, Larkin J 3rd, Panarey L, Aitken MK, Koeberlein B, Lipsky PE, Tomaszewski $\mathrm{JE}, \mathrm{Naji} A$, Caton AJ: CD4+ $\mathrm{T}$ cells recognizing a single selfpeptide expressed by APCs induce spontaneous autoimmune arthritis. J Immuno/ 2008, 180:833-841.

14. Thomas R, Mcllraith M, Davis LS, Lipsky PE: Rheumatoid synovium is enriched in CD45RBdim mature memory $\mathrm{T}$ cells that are potent helpers for B cell differentiation. Arthritis Rheum 1992, 35:1455-1465.

15. Romagnoli P, Strahan D, Pelosi M, Cantagrel A, van Meerwijk JP: A potential role for protein tyrosine kinase p56(lck) in rheumatoid arthritis synovial fluid $\mathrm{T}$ lymphocyte hyporesponsiveness. Int Immunol 2001, 13:305-312.

16. Zhang Z, Gorman CL, Vermi AC, Monaco C, Foey A, Owen S, Amjadi $P$, Vallance A, McClinton C, Marelli-Berg F, Isomäki $P$, Russell A, Dazzi F, Vyse TJ, Brennan FM, Cope AP: TCRzetadim lymphocytes define populations of circulating effector cells that migrate to inflamed tissues. Blood 2007, 109:4328-4335.

17. Zhang Z, Gorman C, Clark JM, Cope AP: Rheumatoid arthritis: a disease of chronic, low-amplitude signals transduced through T cell antigen receptors? Wien Med Wochenschr 2006, 156:210.

18. Allen ME, Young SP, Michell RH, Bacon PA: Altered T lymphocyte signaling in rheumatoid arthritis. Eur J Immunol 1995, 25: 1547-1554.

19. Maurice MM, Lankester AC, Bezemer AC, Geertsma MF, Tak PP, Breedveld FC, van Lier RA, Verweij CL: Defective TCR-mediated signaling in synovial $\mathrm{T}$ cells in rheumatoid arthritis. $J$ Immunol 1997, 159:2973-2978.

20. Dayer JM, Burger D: Cytokines and direct cell contact in synovitis: relevance to therapeutic intervention. Arthritis Res 1999, 1:17-20. 
21. Bottini N, Vang T, Cucca F, Mustelin T: Role of PTPN22 in type 1 diabetes and other autoimmune diseases. Semin Immunol 2006, 18:207-213.

22. Vang $T$, Congia $M$, Macis MD, Musumeci L, Orrú V, Zavattari $P$, Nika K, Tautz L, Taskén K, Cucca F, Mustelin T, Bottini N: Autoimmune-associated lymphoid tyrosine phosphatase is a gain-offunction variant. Nat Genet 2005, 37:1317-1319.

23. Rieck M, Arechiga A, Onengut-Gumuscu S, Greenbaum C, Concannon P, Buckner JH: Genetic variation in PTPN22 corresponds to altered function of $\mathrm{T}$ and $\mathrm{B}$ lymphocytes. J Immunol 2007, 179:4704-4710.

24. Swanberg M, Lidman O, Padyukov L, Eriksson P, Akesson E, Jagodic M, Lobell A, Khademi M, Börjesson O, Lindgren CM, Lundman $P$, Brookes AJ, Kere J, Luthman $H$, Alfredsson L, Hillert J, Klareskog L, Hamsten A, Piehl F, Olsson T: MHC2TA is associated with differential MHC molecule expression and susceptibility to rheumatoid arthritis, multiple sclerosis and myocardial infarction. Nat Genet 2005, 37:486-494.

25. Kitamura $H$, Iwakabe $K$, Yahata $T$, Nishimura $S$, Ohta $A$, Ohmi $Y$, Sato M, Takeda K, Okumura K, Van Kaer L, Kawano T, Taniguchi M, Nishimura T: The natural killer T (NKT) cell ligand alphagalactosylceramide demonstrates its immunopotentiating effect by inducing interleukin (IL)-12 production by dendritic cells and IL-12 receptor expression on NKT cells. J Exp Med 1999, 189:1121-1128.

26. Cavanagh LL, Boyce A, Smith L, Padmanabha J, Filgueira L, Pietschmann $P$, Thomas R: Rheumatoid arthritis synovium contains plasmacytoid dendritic cells. Arthritis Res Ther 2005, 7: R230-R240.

27. Leung BP, Conacher M, Hunter D, Mclnnes IB, Liew FY, Brewer $\mathrm{JM}$ : A novel dendritic cell-induced model of erosive inflammatory arthritis: distinct roles for dendritic cells in T cell activation and induction of local inflammation. J Immuno/ 2002, 169: 7071-7077.

28. Thomas R, Davis LS, Lipsky PE: Rheumatoid synovium is enriched in mature antigen-presenting dendritic cells. J Immunol 1994, 152:2613-2623.

29. Dittel BN, Visintin I, Merchant RM, Janeway CA Jr: Presentation of the self antigen myelin basic protein by dendritic cells leads to experimental autoimmune encephalomyelitis. J Immunol 1999, 163:32-39.

30. Ludewig B, Odermatt B, Landmann S, Hengartner $\mathrm{H}$, Zinkernagel $\mathrm{RM}$ : Dendritic cells induce autoimmune diabetes and maintain disease via de novo formation of local lymphoid tissue. $J$ Exp Med 1998, 188:1493-1501.

31. Sallusto F, Lanzavecchia A: Understanding dendritic cell and Tlymphocyte traffic through the analysis of chemokine receptor expression. Immunol Rev 2000, 177:134-140.

32. Caux C, Massacrier C, Vanbervliet B, Dubois B, van Kooten C, Durand I, Banchereau J: Activation of human dendritic cells through CD40 cross-linking. J Exp Med 1994, 180:1263-1272.

33. O'Sullivan BJ, Thomas R: CD40 Ligation conditions dendritic cell antigen-presenting function through sustained activation of NF-kappaB. J Immuno/ 2002, 168:5491-5498.

34. Nolte MA, Leibundgut-Landmann S, Joffre O, Reis e Sousa C: Dendritic cell quiescence during systemic inflammation driven by LPS stimulation of radioresistant cells in vivo. J Exp Med 2007, 204:1487-1501

35. Pettit AR, MacDonald KPA, O'Sullivan B, Thomas R: Differentiated dendritic cells expressing nuclear RelB are predominantly located in rheumatoid synovial tissue perivascular mononuclear cell aggregates. Arthritis Rheum 2000, 43:791800.

36. Huang Q, Ma Y, Adebayo A, Pope RM: Increased macrophage activation mediated through toll-like receptors in rheumatoid arthritis. Arthritis Rheum 2007, 56:2192-2201.

37. Yoza BK, Hu JY, Cousart SL, Forrest LM, McCall CE: Induction of RelB participates in endotoxin tolerance. J Immunol 2006, 177:4080-4085.

38. Napolitani G, Rinaldi A, Bertoni F, Sallusto F, Lanzavecchia A: Selected Toll-like receptor agonist combinations synergistically trigger a $\mathrm{T}$ helper type 1-polarizing program in dendritic cells. Nat Immuno/ 2005, 6:769-776.

39. Mollah ZUA, Pai S, Moore C, O'Sullivan BJ, Harrison MJ, Peng J, Phillips K, Prins JB, Cardinal J, Thomas R: Abnormal NF-kappa B function characterizes human type 1 diabetes dendritic cells and monocytes. $J$ Immunol 2008, 180:3166-3175.
40. du Montcel ST, Michou L, Petit-Teixeira E, Osorio J, Lemaire I, Lasbleiz S, Pierlot C, Quillet P, Bardin T, Prum B, Cornelis F, Clerget-Darpoux F: New classification of HLA-DRB1 alleles supports the shared epitope hypothesis of rheumatoid arthritis susceptibility. Arthritis Rheum 2005, 52:1063-1068.

41. Gregersen PK, Silver J, Winchester RJ: The shared epitope hypothesis: an approach to understanding the molecular genetics of suseptibility to rheumatoid arthritis. Arthritis Rheum 1987, 30:1205-1213.

42. Silman AJ, Newman J, MacGregor AJ: Cigarette smoking increases the risk of rheumatoid arthritis. Results from a nationwide study of disease-discordant twins. Arthritis Rheum 1996, 39:732-735.

43. Klareskog L, Stolt $P$, Lundberg $K$, Källberg $H$, Bengtsson $C$ Grunewald J, Rönnelid J, Harris HE, Ulfgren AK, RantapääDahlqvist S, Eklund A, Padyukov L, Alfredsson L: A new model for an etiology of rheumatoid arthritis: smoking may trigger HLA-DR (shared epitope)-restricted immune reactions to autoantigens modified by citrullination. Arthritis Rheum 2006, 54:38-46.

44. Padyukov L, Silva C, Stolt P, Alfredsson L, Klareskog L: A geneenvironment interaction between smoking and shared epitope genes in HLA-DR provides a high risk of seropositive rheumatoid arthritis. Arthritis Rheum 2004, 50:3085-3092.

45. Lee WW, Yang ZZ, Li G, Weyand CM, Goronzy JJ: Unchecked CD70 expression on T cells lowers threshold for $T$ cell activation in rheumatoid arthritis. J Immunol 2007, 179:2609-2615.

46. Keffer J, Probert L, Cazlaris H, Georgopoulos S, Kaslaris E, Kioussis D, Kollias G: Transgenic mice expressing human tumour necrosis factor: a predictive genetic model of arthritis. EMBO $J$ 1991, 10:4025-4031.

47. Horai R, Saijo S, Tanioka H, Nakae S, Sudo K, Okahara A, lkuse T, Asano M, Iwakura Y: Development of chronic inflammatory arthropathy resembling rheumatoid arthritis in interleukin 1 receptor antagonist-deficient mice. J Exp Med 2000, 191:313320.

48. Campbell IK, Gerondakis S, O'Donnell K, Wicks IP: Distinct roles for the NF-kappaB1 (p50) and c-Rel transcription factors in inflammatory arthritis. J Clin Invest 2000, 105:1799-1806.

49. Tak PP, Gerlag DM, Aupperle KR, van de Geest DA, Overbeek M, Bennett BL, Boyle DL, Manning AM, Firestein GS: Inhibitor of nuclear factor kappaB kinase beta is a key regulator of synovial inflammation. Arthritis Rheum 2001, 44:1897-1907.

50. O'Sullivan B, Thompson AG, Thomas R: NF-kappa B as a therapeutic target in autoimmune disease. Curr Opin Ther Targets 2007, 11:111-122.

51. O'Sullivan B, Thomas HE, Pai $S$, Santamaria $P$, Iwakura $Y$ Steptoe RJ, Kay TW, Thomas R: IL-1 breaks tolerance through expansion of $\mathrm{CD}^{2} 5^{+}$effector T cells. J Immunol 2006, 176: 7278-7287.

52. Nakae S, Asano M, Horai R, Sakaguchi N, Iwakura Y: IL-1 enhances $T$ cell-dependent antibody production through induction of CD40 ligand and OX40 on T cells. J Immunol 2001, 167:90-97.

53. Ehrenstein MR, Evans JG, Singh A, Moore S, Warnes G, Isenberg $D A$, Mauri C: Compromised function of regulatory $T$ cells in rheumatoid arthritis and reversal by anti-TNFalpha therapy. $J$ Exp Med 2004, 200:277-285.

54. Izumi KM, Kieff ED: The Epstein-Barr virus oncogene product latent membrane protein 1 engages the tumor necrosis factor receptor-associated death domain protein to mediate B lymphocyte growth transformation and activate NF-kappaB. Proc Natl Acad Sci USA 1997, 94:12592-12597.

55. Yang SR, Chida AS, Bauter MR, Shafiq N, Seweryniak K, Maggirwar SB, Kilty I, Rahman I: Cigarette smoke induces proinflammatory cytokine release by activation of NF-kappaB and posttranslational modifications of histone deacetylase in macrophages. Am J Physiol Lung Cell Mol Physiol 2006, 291: L46-L57.

56. Brand JM, Frohn C, Cziupka K, Brockmann C, Kirchner H, Luhm J: Prolactin triggers pro-inflammatory immune responses in peripheral immune cells. Eur Cytokine Netw 2004, 15:99-104.

57. Pai S, O'Sullivan B, Abdul-Jabbar I, Peng J, Connoly G, Khanna R, Thomas R: Nasopharyngeal carcinoma-associated EpsteinBarr virus-encoded oncogene latent membrane protein 1 potentiates regulatory T-cell function. Immunol Cell Biol 2007, 85:370-377. 
58. Quinn MA, Conaghan PG, O'Connor PJ, Karim Z, Greenstein A, Brown A, Brown C, Fraser A, Jarret S, Emery P: Very early treatment with infliximab in addition to methotrexate in early, poor-prognosis rheumatoid arthritis reduces magnetic resonance imaging evidence of synovitis and damage, with sustained benefit after infliximab withdrawal: results from a twelve-month randomized, double-blind, placebo-controlled trial. Arthritis Rheum 2005, 52:27-35.

59. Palanki MS: Inhibitors of AP-1 and NF-kappa B mediated transcriptional activation: therapeutic potential in autoimmune diseases and structural diversity. Curr Med Chem 2002, 9: 219-227.

60. Foxwell B, Browne K, Bondeson J, Clarke C, de Martin R, Brennan $F$, Feldmann $M$ : Efficient adenoviral infection with IkappaB alpha reveals that macrophage tumor necrosis factor alpha production in rheumatoid arthritis is NF-kappaB dependent. Proc Natl Acad Sci USA 1998, 95:8211-8215.

61. Tomita T, Takeuchi E, Tomita N, Morishita R, Kaneko M, Yamamoto K, Nakase T, Seki H, Kato K, Kaneda Y, Ochi T: Suppressed severity of collagen-induced arthritis by in vivo transfection of nuclear factor kappaB decoy oligodeoxynucleotides as a gene therapy. Arthritis Rheum 1999, 42:2532-2542.

62. Robinson MJ, Sancho D, Slack EC, LeibundGut-Landmann S, Reis e Sousa C: Myeloid C-type lectins in innate immunity. Nat Immunol 2006, 7:1258-1265.

63. Remmers EF, Plenge RM, Lee AT, Graham RR, Hom G, Behrens TW, de Bakker PI, Le JM, Lee HS, Batliwalla F, Li W, Masters SL, Booty MG, Carulli JP, Padyukov L, Alfredsson L, Klareskog L, Chen WV, Amos Cl, Criswell LA, Seldin MF, Kastner DL, Gregersen PK: STAT4 and the risk of rheumatoid arthritis and systemic lupus erythematosus. N Engl J Med 2007, 357:977986.

64. Plenge RM, Seielstad M, Padyukov L, Lee AT, Remmers EF, Ding B, Liew A, Khalili H, Chandrasekaran A, Davies LR, Li W, Tan AK, Bonnard C, Ong RT, Thalamuthu A, Pettersson S, Liu C, Tian C, Chen WV, Carulli JP, Beckman EM, Altshuler D, Alfredsson L, Criswell LA, Amos Cl, Seldin MF, Kastner DL, Klareskog L, Gregersen PK: TRAF1-C5 as a risk locus for rheumatoid arthritis: a genomewide study. N Engl J Med 2007, 357:1199-1209.

65. Lorentzen JC, Flornes L, Eklöw C, Bäckdahl L, Ribbhammar U, Guo JP, Smolnikova M, Dissen E, Seddighzadeh M, Brookes AJ, Alfredsson L, Klareskog L, Padyukov L, Fossum S: Association of arthritis with a gene complex encoding C-type lectin-like receptors. Arthritis Rheum 2007, 56:2620-2632.

66. Balandraud N, Meynard JB, Auger I, Sovran H, Mugnier B, Reviron $D$, Roudier J, Roudier C: Epstein-Barr virus load in the peripheral blood of patients with rheumatoid arthritis: accurate quantification using real-time polymerase chain reaction. Arthritis Rheum 2003, 48:1223-1228.

67. Balandraud N, Roudier J, Roudier C: Epstein-Barr virus and rheumatoid arthritis. Autoimmun Rev 2004, 3:362-367.

68. Hiscott J, Kwon H, Genin P: Hostile takeovers: viral appropriation of the NF-kappaB pathway. J Clin Invest 2001, 107:143151.

69. Toussirot E, Roudier J: Pathophysiological links between rheumatoid arthritis and the Epstein-Barr virus: an update. Joint Bone Spine 2007, 74:418-426.

70. Pratesi F, Tommasi C, Anzilotti C, Chimenti D, Migliorini P: Deiminated Epstein-Barr virus nuclear antigen 1 is a target of anticitrullinated protein antibodies in rheumatoid arthritis. Arthritis Rheum 2006, 54:733-741.

71. Anzilotti C, Riente L, Pratesi F, Chimenti D, Delle Sedie A, Bombardieri S, Migliorini $P$ : IgG, IgA, IgM antibodies to a viral citrullinated peptide in patients affected by rheumatoid arthritis, chronic arthritides and connective tissue disorders. Rheumatology (Oxford) 2007, 46:1579-1582.

72. Roudier J, Petersen J, Rhodes GH, Luka J, Carson DA: Susceptibility to rheumatoid arthritis maps to a T-cell epitope shared by the HLA-Dw4 DR b-1 chain and the Ebstein-Barr virus glycoprotein gp110. Proc Natl Acad Sci USA 1989, 86:51045108.

73. Sawada S, Takei M: Epstein-Barr virus etiology in rheumatoid synovitis. Autoimmun Rev 2005, 4:106-110.

74. Gaston JS, Rickinson AB, Yao QY, Epstein MA: The abnormal cytotoxic $T$ cell response to Epstein-Barr virus in rheumatoid arthritis is correlated with disease activity and occurs in other arthropathies. Ann Rheum Dis 1986, 45:932-936.
75. Cahir-McFarland ED, Carter K, Rosenwald A, Giltnane JM, Henrickson SE, Staudt LM, Kieff E: Role of NF-kappa B in cell survival and transcription of latent membrane protein 1-expressing or Epstein-Barr virus latency III-infected cells. $J$ Virol 2004, 78:4108-4119.

76. Khanna R, Bell S, Sherritt M, Galbraith A, Burrows SR, Rafter L, Clarke B, Slaughter R, Falk MC, Douglass J, Williams T, Elliott SL, Moss DJ: Activation and adoptive transfer of Epstein-Barr virus-specific cytotoxic $T$ cells in solid organ transplant patients with posttransplant lymphoproliferative disease. Proc Natl Acad Sci USA 1999, 96:10391-10396.

77. Weyand CM, Goronzy JJ, Kurtin PJ: Lymphoma in rheumatoid arthritis: an immune system set up for failure. Arthritis Rheum 2006, 54:685-689.

78. Tan LC, Mowat AG, Fazou C, Rostron T, Roskell H, Dunbar PR, Tournay C, Romagné F, Peyrat MA, Houssaint E, Bonneville M, Rickinson AB, McMichael AJ, Callan MF: Specificity of T cells in synovial fluid: high frequencies of $\mathrm{CD}^{+} \mathrm{T}$ cells that are specific for certain viral epitopes. Arthritis Res 2000, 2:154-164.

79. Klatt T, Ouyang $\mathrm{Q}$, Flad T, Koetter I, Buhring HJ, Kalbacher $\mathrm{H}$ Pawelec G, Muller CA: Expansion of peripheral CD8 ${ }^{+}$CD28- T cells in response to Epstein-Barr virus in patients with rheumatoid arthritis. J Rheumatol 2005, 32:239-251. 